\title{
Wnt5a Regulates Odontoblast Inflammation by Promoting CCL2 Expression
}

\section{Ronghua Zhang}

School of Stomatology of Lanzhou University

Wei Ge

School of Stomatology of Lanzhou University

\section{Ruixue Huang}

School of Stomatology of Lanzhou University

Zhao Meng

School of Stomatology of Lanzhou University

\section{Xiaojie Xu}

School of Stomatology of Lanzhou University

Xuesheng Liu

School of Stomatology of Lanzhou University

Yuan Zhao ( $\sim$ zhaoy@lzu.edu.cn )

School of Stomatology of Lanzhou University

\section{Research Article}

Keywords: odontoblasts, Wnt5a, pulp inflammation, TNF-a

Posted Date: April 12th, 2021

DOI: https://doi.org/10.21203/rs.3.rs-397037/v1

License: (c) (i) This work is licensed under a Creative Commons Attribution 4.0 International License.

Read Full License 


\section{Wnt5a Regulates Odontoblast Inflammation by Promoting CCL2 Expression}

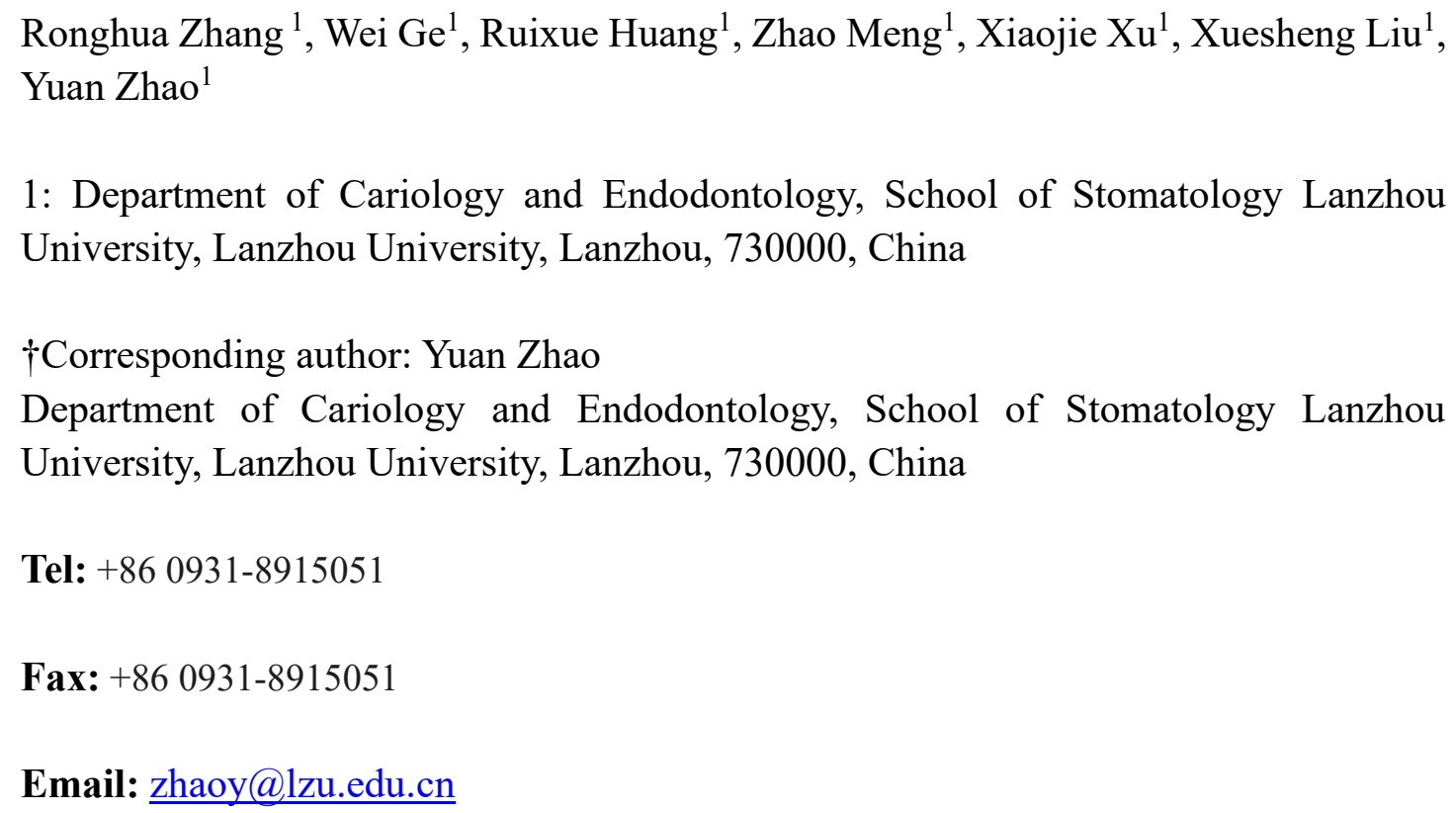

Keyword: odontoblasts; Wnt5a; pulp inflammation; TNF- $\alpha$

Date: Friday, April 9, 2021

\section{Abstract}




\section{Objective}

Wnt5a is involved inflammation, including pulpitis, by upregulating cytokine/chemokine expression. Odontoblasts are the first layer cells in dental pulp and respond to inflammatory stimuli. However, whether Wnt5a is involved in odontoblast inflammation is unclear. This study aimed to investigate the role of Wnt5a in odontoblast inflammation.

\section{Methods}

We measured and compared Wnt5a- or TNF- $\alpha$-induced cytokine/chemokine expression in mouse odontoblast-like (17IIA11) cells by real-time PCR and Western blotting. Transwell assays were used to examine the effect of Wnt5a on RAW264.7 macrophage migration. We examined whether the nuclear factor-kappa $\mathrm{B}(\mathrm{NF}-\mathrm{\kappa B})$ and mitogen-activated protein kinase (MAPK) pathways were involved in the molecular mechanism of TNF- $\alpha$ or Wnt5a in 17IIA11 cells by Western blotting.

\section{Results}

TNF- $\alpha$ upregulated Wnt5a in odontoblasts. Wnt5a upregulated CCL2 expression in odontoblasts and enhanced RAW264.7 cell migration. We also found that TNF- $\alpha$-induced Wnt5a expression was abrogated by inhibiting the MAPK pathway or NF- $\mathrm{KB}$ activity and that inhibiting MAPK activity could lead to decreased NF- $\mathrm{KB}$ activity.

\section{Conclusions}

Wnt5a is involved in the TNF- $\alpha$-induced inflammatory response in odontoblasts. TNF- $\alpha$ upregulates Wnt5a expression via MAPK-dependent NF- $\mathrm{BB}$ activation in odontoblasts. Wnt5a upregulates CCL2 expression in odontoblasts and enhances RAW264.7 macrophage migration.

\section{Key Words}

odontoblasts; Wnt5a; pulp inflammation; TNF- $\alpha$

\section{Introduction}

The Wnt signaling pathway is an evolutionarily conserved signaling pathway that regulates embryonic development, tissue regeneration, and various types of inflammation [1-5]. The $\beta$ catenin-dependent Wnt signaling pathway is the canonical Wnt signaling pathway, while the $\beta$ catenin-independent pathway is the noncanonical Wnt signaling pathway [6].

Wnt5a is a member of the Wnt signaling family and is involved in the activation of noncanonical Wnt signaling; Wnt5a is also involved in regulating various type of inflammation, including rheumatoid arthritis, periodontitis, and pulpitis [7-11]. In addition, Wnt5a induces the expression of multiple cytokines/chemokines, including IL-6, IL-8, IL-17, CXCL1, and CCL2, and indirectly activates the migration of immune cells in human dental pulp cell (hDPC) populations $[9,10]$.

Pulp inflammation, also called pulpitis, is a major oral health problem caused by the invasion of microorganisms and their components via dentinal tubules in the pulp [12] that frequently leads to persistent and referred pain. Pulpitis often results in root canal therapy, whose disadvantages include the loss of living pulp and increased tooth brittleness. Therefore, we hope to provide a theoretical basis for the development of new treatments for pulpitis by 
understanding pulpitis pathogenesis.

Odontoblasts are the first layer cells in dental pulp, and the main function of odontoblasts is dentin formation. During pulpitis, odontoblasts are the first cells encountered by invading bacteria, and the products of these bacteria are located at the pulp-dentin interface $[13,14]$. Numerous studies have shown that odontoblasts are involved in pulp immune and inflammatory responses to bacteria and their components $[15,16]$. In addition, odontoblasts produce Tumor necrosis factors-alpha (TNF- $\alpha$ ), IL-6, IL-8, CCL2, CXCL10 and IL-10 in response to inflammatory stimuli $[17,18]$. However, it is unclear whether Wnt5a is involved in regulating the inflammatory response of odontoblasts.

The mitogen-activated protein kinase (MAPK) pathway, including its three main members $\mathrm{p} 38$ MAP kinase (p38 MAPK), c-Jun N-terminal kinase (JNK), and extracellular signal-regulated protein kinase 1/2 (ERK 1/2), is an important signaling pathway related to inflammation. A number of studies have shown that MAPK is involved in the inflammatory response, and inflammatory stimuli such as proinflammatory chemokines and cytokines can activate the MAPK pathway [1921]. The nuclear factor-kappa $B(\mathrm{NF}-\kappa \mathrm{B})$ pathway is another important signaling pathway involved in regulating inflammation [22]. Furthermore, P65 phosphorylation is required for the optimal activation of NF-kB-dependent gene transcription [23-25].

TNF- $\alpha$ is a well-known inflammatory cytokine that can cause dental pulp inflammation [26]. Both NF- $\mathrm{KB}$ and MAPK are critical for inducing the expression of genes involved in inflammation $[13,27]$ and are linked to Wnt5a-stimulated signaling $[10,28]$. In previous experiments, we demonstrated that TNF- $\alpha$ upregulates the expression of Wnt5a in hDPC through the MAPK and NF- $\kappa$ B pathways $[9,10]$. However, whether Wnt5a regulates odontoblast inflammation and the crosstalk between NF- $\mathrm{\kappa B}$ and MAPK is poorly understood.

In this study, we investigated the role of Wnt5a in odontoblast inflammation and the potential signaling pathways by which TNF- $\alpha$ upregulates Wnt5a expression in odontoblasts.

\section{Materials and Methods}

Cell Lines and Culture

The 17IIA11 cell line was grown and maintained in Alpha Modification of Minimum Essential Medium Eagle ( $\alpha$-MEM) supplemented with $10 \%$ fetal bovine serum (FBS) in a humidified atmosphere containing 5\% CO2 at $37{ }^{\circ} \mathrm{C}$. 17IIA11 cells were treated with recombinant human TNF- $\alpha$ (rhTNF- $\alpha, 10 \mathrm{ng} / \mathrm{ml}$, Invivogen, San Diego, CA) or recombinant human Wnt5a (rhWnt5a, $500 \mathrm{ng} / \mathrm{ml}, \mathrm{R} \& \mathrm{D}$ Systems) for the indicated times. To examine the signaling pathways, cells were pretreated with one of the following specific pathway inhibitors: BAY11-7082 (an NF-kB inhibitor, $10 \mathrm{mM}$, Beyotime Institute of Biotechnology, Shanghai, China), SB203580 (a p38 MAPK inhibitor, $20 \mu \mathrm{M}$, Cell Signaling Technology, Danvers, MA), SP600125 (a JNK inhibitor, $10 \mu \mathrm{M}$, Merck), or U0126 (an ERK inhibitor, $10 \mu \mathrm{M}$, Merck).

The RAW 264.7 macrophage cell line was purchased from the American Type Culture Collection (ATCC). These cells were cultured in RPMI 1640 with $10 \%$ FBS, 2 mM Lglutamine, $50 \mathrm{U} / \mathrm{ml}$ penicillin, and $50 \mu \mathrm{g} / \mathrm{ml}$ streptomycin in a humidified atmosphere containing $5 \% \mathrm{CO} 2$ at $37{ }^{\circ} \mathrm{C}$.

\section{Real-time Reverse Transcriptase-Polymerase Chain Reaction (RT-PCR)}

Total RNA was extracted using TRIzol reagent (Invitrogen) according to the manufacturer's 
instructions. One microgram of mRNA was reverse transcribed using the RT reagent kit (Takara Biotechnology, Dalian, Liaoning, China), and real-time PCR was performed using Sso Advanced ${ }^{\mathrm{TM}}$ SYBR ${ }^{\circledR}$ Green Super Mix. The primer sequences used for real-time RT-PCR were as follows: Wnt5a, 5'-CAGTTCAAGACCGTGCAGAC-3' (forward) and 5'GCACCCACTACTTGCACACA-3' (reverse); IL-6, 5'-ACCTTCCAAAGATGGCTGAA-3' (forward) and 5'-GCTCTGGCTTGTTCCTCACT-3' (reverse); IL-8, 5'CACTCCATAAGGCACAAACTTTC-3' (forward) and 5'-GCCAGCTTGGAAGTCATGTT-3' (reverse); GAPDH, 5'-TCAACAGCGACACCCACTC-3' (forward) and 5'GCTGTAGCCAAATTCGTTGTC-3' (reverse); CXCL1, 5'ACTGGTGGCTGTTCCTGAAG-3' (forward) and 5'-CTTCTCCTAAGCGATGCTCAA-3' (reverse); and CCL2, 5'-CTGCTCATAGCAGCCACCTT-3' (forward) and 5'CAGGTGACTGGGGCATTGAT-3' (reverse). The results were analyzed with the $\Delta \Delta C T$ method, and the relative amount or fold change in the target gene was normalized to the level of GAPDH. All real-time RT-PCR analyses were performed in triplicate.

\section{Western Blot Analysis}

Western blot analysis was performed as previously described [10]. In brief, 17IIA11 cells were treated with TNF- $\alpha(10 \mathrm{ng} / \mathrm{ml})$ or Wnt5a $(500 \mathrm{ng} / \mathrm{ml})$ for different times. The cells were lysed in RIPA buffer (50 mM Tris-HCl, pH 7.4, 2 mM EDTA, and 2\% SDS) supplemented with a proteinase inhibitor mixture (Roche R\&D Center China, Shanghai, China). Cell protein samples were subjected to $10 \%$ SDS polyacrylamide gel electrophoresis and transferred to PVDF membranes by a semidry transfer apparatus. To examine signaling pathways, the following antibodies from Cell Signaling Technology were used: phospho-P65 (catalog no. 3033), P65 (catalog no. 8242), phospho-ERK (catalog no. 4370), ERK (catalog no. 4695), phospho-p38 (catalog no. 4511), p38 (catalog no. 9212), phospho-JNK (catalog no. 4668), and JNK (catalog no. 9258).

Cytokine and Chemokine Analyses

IL-6, IL-8 and CCL2 in Wnt5a-treated or TNF- $\alpha$-stimulated cells were measured using RTPCR.

\section{Transwell Migration Assay}

The migratory capacity of macrophages was examined using Transwell chambers (3- $\mu \mathrm{m}$ pore, Corning) in triplicate. 17IIA11 cells were cultured with or without rhWnt5a treatment for $48 \mathrm{~h}$ before supernatants were collected. Then, $200 \mu \mathrm{l}$ of macrophages $\left(2 \times 10^{6} / \mathrm{ml}\right)$ was seeded in the upper chamber in serum-free RPMI 1640, and $600 \mu$ of culture supernatant from untreated or Wnt5a-treated 17IIA11 cells was added to the lower well. rhWnt5a was also added to the bottom well. After $4 \mathrm{~h}$ of incubation, the membranes were removed, and the underside of the polycarbonate membrane was stained with $1 \%$ crystal violet for $30 \mathrm{~min}$. Then, the number of migrating cells was counted in five randomly selected fields under light microscopy.

\section{Statistical Analysis}

Each experiment was repeated at least three times, and the results are expressed as the means \pm standard deviation (SD). The statistical significance of differences was determined 
using ANOVA. A value of $p<0.05$ was considered statistically significant.

\section{Results}

\section{TNF- $\alpha$ upregulated Wnt5a expression in 17IIA11 cells through MAPK and NF-кB activation}

We treated 17IIA11 cells with TNF- $\alpha$ and found that TNF- $\alpha$ not only promoted the upregulation of Wnt5a expression but also significantly promoted the phosphorylation of ERK1/2, P38, JNK and P65 (Fig. 1 a-e).

TNF- $\alpha$ has been shown to activate the NF- $\mathrm{kB}[23,29]$ and MAPK signaling pathways [30]. To explore whether the NF- $\mathrm{KB}$ and MAPK pathways are involved in the process of TNF- $\alpha$ upregulation of Wnt5a expression, we used inhibitors of the MAPK and NF- $\mathrm{kB}$ pathways. Western blot results showed that inhibition of the MAPK and NF- $\mathrm{KB}$ pathways significantly inhibited the expression of Wnt5a induced by TNF- $\alpha$ (Fig. $1 \mathrm{f}-\mathrm{i}$ ).

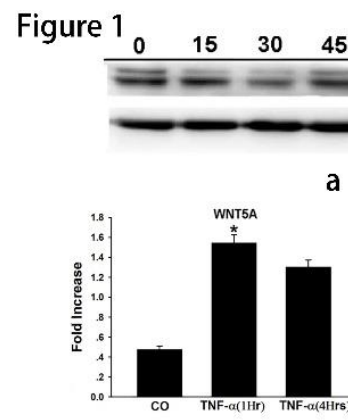

b

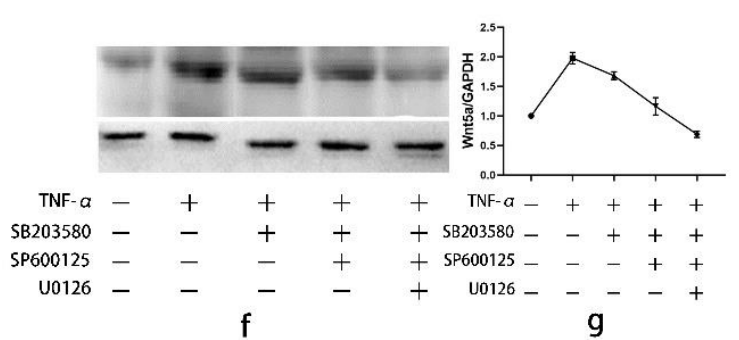

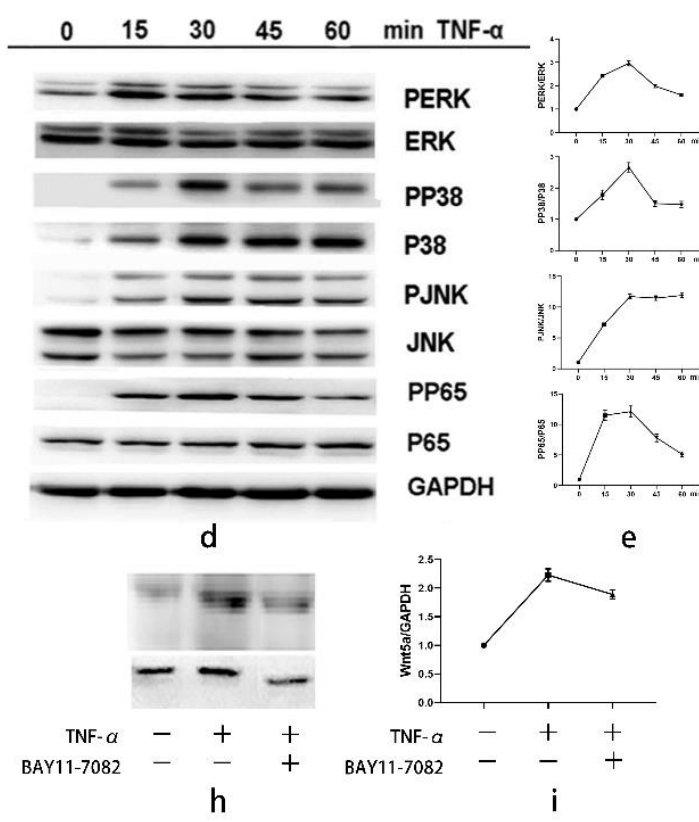

$\mathrm{h}$

Figure 1. TNF- $\alpha$ induces the upregulation of Wnt5a through the MAPK and NF- $\kappa B$ pathways (these results are from different parts of the same gel). a, c: Western blot showing the protein expression of Wnt5a after odontoblasts were stimulated with TNF- $\alpha$ for the indicated time. $b$ : Wnt5a mRNA expression in odontoblasts stimulated by TNF- $\alpha$ for the indicated time. $d$ and e: Protein expression of total and phosphorylated ERK, P38, JNK, and P65after odontoblasts were stimulated with TNF- $\alpha$ for of the indicated time. $f$ and g: Effect of inhibiting the phosphorylation of ERK, P38, JNK, and P65 on Wnt5a expression. SP600125 (a JNK inhibitor), SB203580 (a p38 inhibitor), and U0126 (an ERK inhibitor). p-p38, phospho-p38; pJNK, phospho-JNK; pERK, phospho-ERK. GAPDH was used as a control. *, $p<0.05$ versus the control (CO).

\section{TNF- $\alpha$ upregulated the expression of Wnt5a through the MAPK-dependent NF-кB pathway}

TNF- $\alpha$-induced Wnt5a expression was markedly decreased in the presence of specific MAPK or NF- $\kappa B$ pathway inhibitors. However, the crosstalk between NF- $\kappa B$ and MAPK is poorly understood. Therefore, we examined whether the phosphorylation of NF- $\mathrm{KB}$ and MAPK were 
affected by each other in the presence of specific inhibitors. At the indicated concentration, these inhibitors did not influence cell viability as assessed by the MTT assay (data not shown). Interestingly, we found that inhibiting MAPK activity significantly abrogated TNF- $\alpha$-induced NF$\kappa B$ activation. However, inhibiting NF- $\kappa B$ activity did not affect TNF- $\alpha$-induced MAPK activation (Fig. 2).

Figure 2 PP65 P65

PP38

P38

P-JNK

JNK

P-ERK

ERK

GAPDH

TNF- $\alpha$

BAY11-7082

SB203580

SP600125

U0126
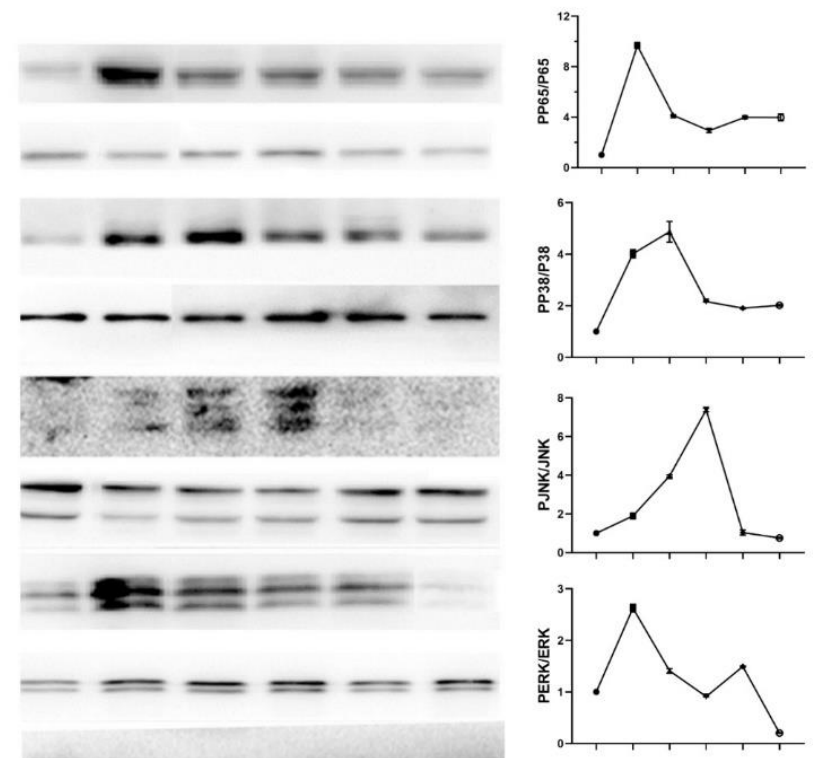

Figure 2. Western blot detected the protein expression of NF- $\mathrm{kB}$ and MAPK pathways (these results are from different parts of the same gel). GAPDH was used as a control. PP65, phospho-65; PP38, phospho-P38; PJNK, phospho-JNK; PERK, phospho-ERK. BAY11-7082 (an NF-kB inhibitor); SP600125 (a JNK inhibitor), SB203580 (a p38 inhibitor), or U0126 (an ERK inhibitor).

\section{Wnt5a induced CCL2 expression and enhanced RAW264.7 cell migration}

We investigated how Wnt5a responds to inflammatory stimuli and whether Wnt5a activates the MAPK and NF- $\mathrm{kB}$ pathways in odontoblasts. First, we measured the cytokines and chemokines that were induced by TNF- $\alpha$ and found that TNF- $\alpha$ upregulated the expression of IL-8, CXCL1, and CCL2 (Fig. 3 a-c). Then, we treated 17IIA11 cells with Wnt5a and found that CCL2 was obviously upregulated by Wnt5a (Fig. 3 d-e). Because Wnt5a induces CCL2 expression, we examined whether macrophages were attracted to Wnt5a. Therefore, RAW264.7 cells were subjected to a Transwell assay. We found that the supernatant of 17IIA11 cells treated with Wnt5a enhanced the migration of RAW264.7 cells (Fig. 3 f-g). Moreover, Wnt5a activated the NF- $\mathrm{KB}$ and MAPK pathways in odontoblasts (Fig. 3 ) 


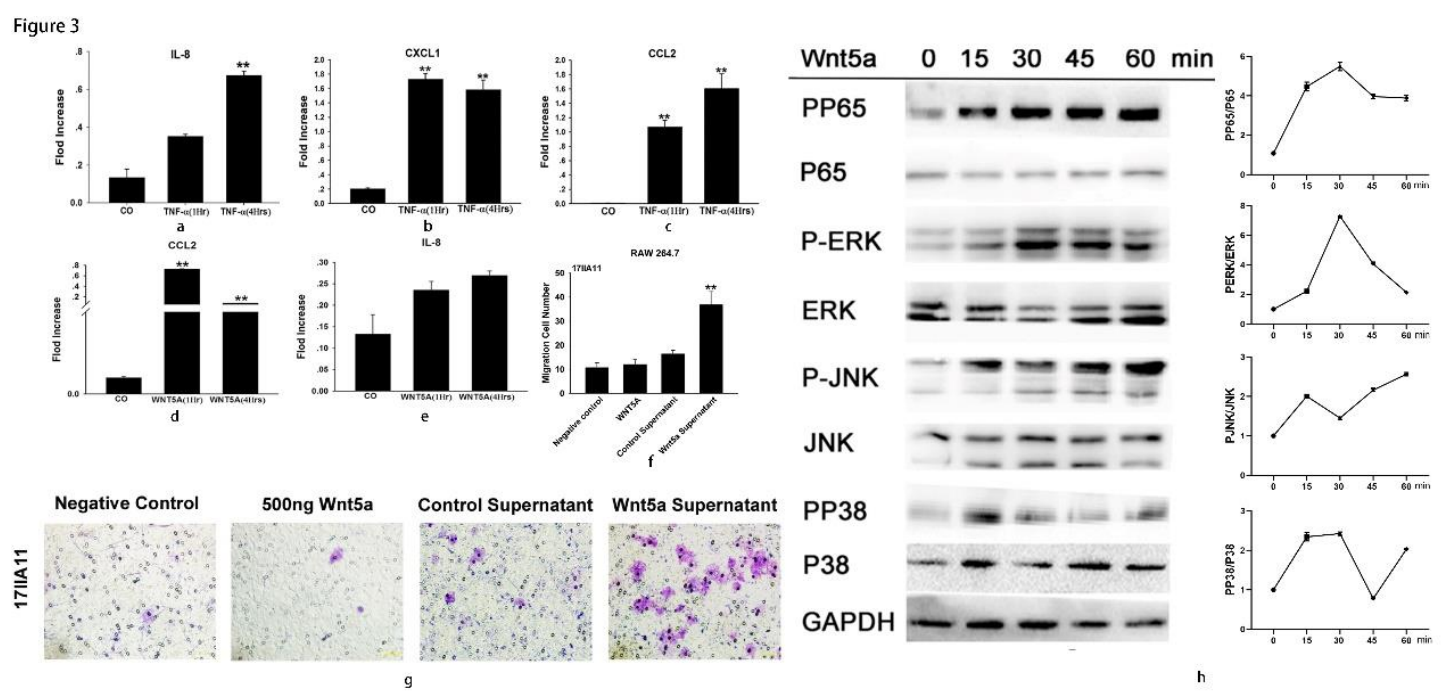

Figure 3. Wnt5a induces CCL2 expression and enhances macrophage migration. In addition, Wnt5a activates the MAPK and NF- $\mathrm{kB}$ signaling pathways. a-e: The mRNA expression of cytokines and chemokines. f, g: Transwell detected the migration of RAW 264.7 cells. h: On the left side is the result that Western blot detected the protein expression of NF- $\mathrm{KB}$ and MAPK pathways (these results are from different parts of the same gel); on the right is the ratio of phosphorylated protein to non-phosphorylated protein of MAPK and NF- $\mathrm{kB}$ pathway related proteins. ${ }^{* *}, p<0.01$ versus the control. GAPDH was used as a control.

\section{Summary of results}

In this study, we first verified whether TNF- $\alpha$ induces the upregulation of Wnt5a and its pathway in odontoblasts and then explored how Wnt5a responds to inflammatory stimuli in odontoblasts. We found that TNF- $\alpha$-induced Wnt5a upregulation occurs through MAPKdependent NF- $\mathrm{KB}$ activation and that Wnt5a upregulates CCL2 expression. In addition, Wnt5a enhanced macrophage migration (Fig. 4). 


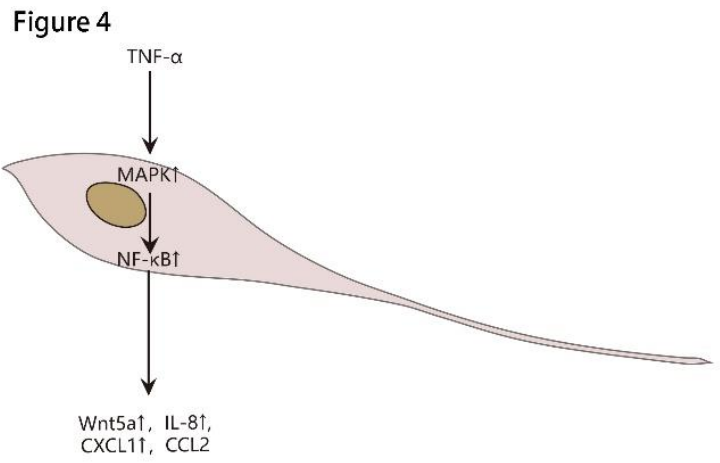

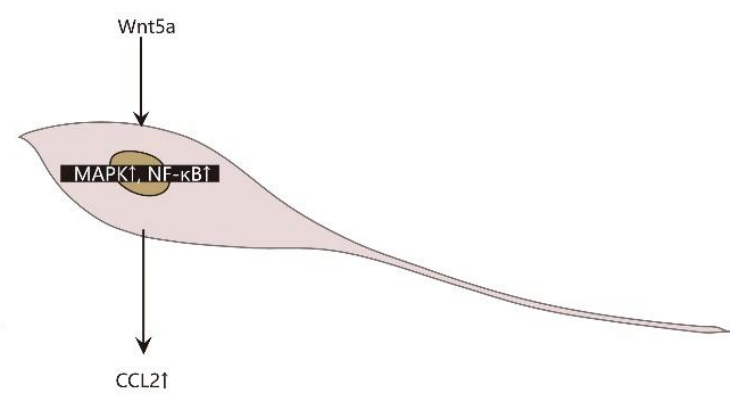

b

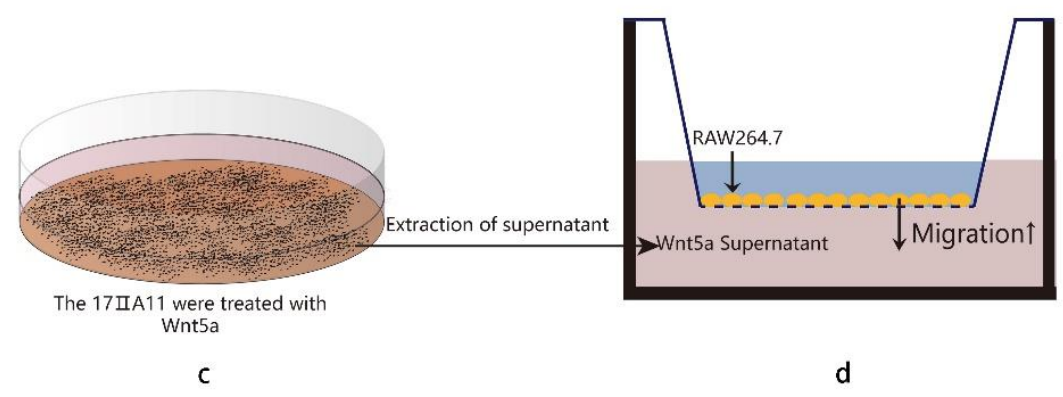

Figure 4. a: TNF- $\alpha$ promotes Wnt5a expression through MAPK and NF- $\kappa B$ activation in 17IIA11 cells and significantly upregulates IL-8, CXCL1, and CCL2 expression. b: Wnt5a activates the NF- $\mathrm{KB}$ and MAPK pathways and upregulates the expression of CCL2. c, d: The supernatant of 17IIA11 cells treated with Wnt5a promotes the migration of RAW264.7 cells.

\section{Discussion}

Studies have confirmed that Wnt5a can regulate a variety of inflammatory responses including the response to pulpitis $[9,10,31,32]$. In $\mathrm{hDPC}$, Wnt5a can not only promote the upregulation of the expression of cytokines and chemokines induced by TNF- $\alpha$ but can also itself increase the levels of cytokines and chemokines in DPCs [10]. Therefore, Wnt5a itself is an inflammatory factor. Odontoblasts are the outermost cells of the dental pulp tissue and are the first line of defense for this tissue against various external stimuli. However, whether Wnt5a is involved in odontoblast inflammation is unclear. We found that TNF- $\alpha$ upregulated the expression of Wnt5a in odontoblasts, and Wnt5a in turn upregulated the expression of CCL2 in odontoblasts. In addition, the supernatant of 17IIA11 cells treated with Wnt5a enhanced the migration of RAW264.7 cells. Therefore, the main role of Wnt5a in odontoblasts is to chemoattract immune cells to migrate to inflammation sites by promoting the expression of chemokines.

Both NF-kB and MAPK are important signaling pathways in inflammation [13, 27]. In hDPC, TNF- $\alpha$ upregulates the expression of Wnt5a through the MAPK and NF- $\kappa B$ pathways [10]. However, the crosstalk between the NF- $\mathrm{KB}$ and MAPK pathways and whether Wnt5a activates the MAPK and NF- $\mathrm{KB}$ pathways in odontoblasts is unclear. In this study, we showed that TNF- $\alpha$ upregulates the expression of Wnt5a through the MAPK-dependent NF- $\mathrm{kB}$ pathway. When Wnt5a is involved in the inflammatory process, it also activates the MAPK pathway (including ERK1/2, P38, JNK) and the NF- $\mathrm{BB}$ pathway $[10,33]$. Both the MAPK and NF- $\mathrm{KB}$ pathways are also involved in the upregulation of cytokine and chemokine expression $[9,34]$. In this study, we demonstrated that 
Wnt5a not only activates the MAPK and NF- $\mathrm{KB}$ pathways but also upregulates the expression of CCL2 in odontoblasts. Therefore, Wnt5a may upregulate the expression of CCL2 via the MAPK and NF- $\kappa B$ pathways.

In addition, Wnt5a is involved in the development of teeth and the differentiation of odontoblasts $[35,36]$. Under inflammatory conditions, the expression of mineralization-related genes is also upregulated through Wnt5a in hDPC [37, 38]. In this study, we did not explore the effects of inflammatory stimuli on the mineralization ability of odontoblasts. We intend to investigate whether Wnt5a involved in the mineralization process of odontoblasts induced by inflammation in subsequent experiments.

In summary, we have demonstrated that Wnt5a is induced by TNF- $\alpha$ via MAPK-dependent NF$\kappa \mathrm{B}$ activation in odontoblasts and that Wnt5a regulates the expression of CCL2. In addition, Wnt5a indirectly promotes macrophage migration.

\section{Conclussion}

Wnt5a is involved in the TNF- $\alpha$-induced inflammatory response in odontoblasts. TNF- $\alpha$ upregulates Wnt5a expression via MAPK-dependent NF- $\mathrm{BB}$ activation in odontoblasts. Wnt5a upregulates CCL2 expression in odontoblasts and enhances RAW264.7 macrophage migration.

\section{Declarations}

Ethics approval and consent to participate: Not applicable.

Consent for publication: Not applicable.

Availability of data and materials: All data generated or analysed during this study are included in this published article.

Competing interests: The authors declare that they have no competing interests.

Funding: Natural Science Foundation of Gansu Province (20JR10RA594)

Authors' contributions: RZ and WG completed experiments and data analysis, and wrote articles. $\mathrm{RH}$ and $\mathrm{ZM}$ participated in the production of the pictures and the writing of the captions. $\mathrm{XX}$ and XL participated in the revision of the article, including spelling and grammar. YZ designed the experiment, guided the implementation of the experiment and the writing of the article, and received funding support.

Acknowledgements: We thank everyone who helped to complete this study.

\section{List of abbreviations}

\begin{tabular}{ll}
\hline Full spelling & Abbreviations \\
\hline mitogen-activated protein kinase & MAPK \\
c-Jun N-terminal kinase & JNK \\
extracellular signal-regulated protein kinase 1/2 & ERK 1/2 \\
nuclear factor-kappa B & NF- $\mathrm{kB}$ \\
tumor necrosis factor-alpha & TNF- $\alpha$ \\
human dental pulp cell & hDPC \\
fetal bovine serum & FBS \\
Real-time Reverse Transcriptase-Polymerase Chain Reaction & RT-PCR \\
\hline
\end{tabular}




\section{References}

1. Mazzotta S, Neves C, Bonner RJ, Bernardo AS, Docherty K, Hoppler S: Distinctive Roles of Canonical and Noncanonical Wnt Signaling in Human Embryonic Cardiomyocyte Development. Stem cell reports 2016, 7(4):764-776.doi:10.1016/j.stemcr.2016.08.008.

2. Finco I, Lerario AM, Hammer GD: Sonic Hedgehog and WNT Signaling Promote Adrenal Gland Regeneration in Male Mice. Endocrinology 2018, 159(2):579-596.doi:10.1210/en.2017-03061.

3. Qiu W, Lei M, Zhou L, Bai X, Lai X, Yu Y, Yang T, Lian X: Hair follicle stem cell proliferation, Akt and Wnt signaling activation in TPA-induced hair regeneration. Histochemistry and cell biology 2017, 147(6):749-758.doi:10.1007/s00418-017-1540-1.

4. Fawzy El-Sayed KM, Hein D, Dörfer CE: Retinol/inflammation affect stemness and differentiation potential of gingival stem/progenitor cells via $W n t / \beta$-catenin. Journal of periodontal research 2019, 54(4):413-423.doi:10.1111/jre.12643.

5. Liu Y, Almeida M, Weinstein RS, O'Brien CA, Manolagas SC, Jilka RL: Skeletal inflammation and attenuation of Wnt signaling, Wnt ligand expression, and bone formation in atherosclerotic ApoE-null mice. American journal of physiology Endocrinology and metabolism 2016, 310(9):E762-773.doi:10.1152/ajpendo.00501.2015.

6. Komiya Y, Habas R: Wnt signal transduction pathways. Organogenesis 2008, 4(2):6875.doi:10.4161/org.4.2.5851.

7. Wang $\mathrm{W}, \mathrm{Yu} \mathrm{X}, \mathrm{Wu} \mathrm{C}$, Jin $\mathrm{H}$ : Differential effects of Wnt5a on the proliferation, differentiation and inflammatory response of keratinocytes. Molecular medicine reports 2018, 17(3):40434048.doi:10.3892/mmr.2017.8358.

8. Maekawa T, Kulwattanaporn P, Hosur K, Domon H, Oda M, Terao Y, Maeda T, Hajishengallis G: Differential Expression and Roles of Secreted Frizzled-Related Protein 5 and the Wingless Homolog Wnt5a in Periodontitis. Journal of Dental Research 2017, 96(5):571577.doi:10.1177/0022034516687248.

9. Liu M, Zhao Y, Wang C, Luo H, A P, Ye L: Interleukin-17 plays a role in pulp inflammation partly by WNT5A protein induction. Archives of oral biology 2019, 103:3339.doi:10.1016/j.archoralbio.2019.05.003.

10. Zhao Y, Wang CL, Li RM, Hui TQ, Su YY, Yuan $Q$, Zhou XD, Ye L: Wnt5a promotes inflammatory responses via nuclear factor kappaB (NF-kappaB) and mitogen-activated protein kinase (MAPK) pathways in human dental pulp cells. The Journal of Biological Chemistry 2014, 289(30):2102821039.doi:10.1074/jbc.M113.546523.

11. MacLauchlan S, Zuriaga MA, Fuster JJ, Cuda CM, Jonason J, Behzadi F, Duffen JP, Haines GK, 3rd, Aprahamian T, Perlman H et al: Genetic deficiency of Wnt5a diminishes disease severity in a murine model of rheumatoid arthritis. Arthritis Research \& Therapy 2017, 19(1):166.doi:10.1186/s13075-017-1375-0.

12. Ko YJ, Kwon KY, Kum KY, Lee WC, Baek SH, Kang MK, Shon WJ: The Anti-Inflammatory Effect of Human Telomerase-Derived Peptide on P. gingivalis Lipopolysaccharide-Induced Inflammatory Cytokine Production and Its Mechanism in Human Dental Pulp Cells. Mediators Inflamm 2015, 2015:385127.doi:10.1155/2015/385127.

13. He W, Zhang $Y$, Zhang J, Yu Q, Wang P, Wang Z, Smith AJ: Cytidine-phosphate-guanosine oligonucleotides induce interleukin-8 production through activation of TLR9, MyD88, NFkappaB, and ERK pathways in odontoblast cells. Journal of endodontics 2012, 38(6):780- 
785.doi:10.1016/j.joen.2012.02.026.

14. Farges JC, Bellanger A, Ducret M, Aubert-Foucher E, Richard B, Alliot-Licht B, Bleicher F, Carrouel F: Human odontoblast-like cells produce nitric oxide with antibacterial activity upon TLR2 activation. Frontiers in Physiology 2015, 6:185.doi:10.3389/fphys.2015.00185.

15. Veerayutthwilai O, Byers MR, Pham TT, Darveau RP, Dale BA: Differential regulation of immune responses by odontoblasts. Oral microbiology and immunology 2007, 22(1):513.doi:10.1111/j.1399-302X.2007.00310.x.

16. Farges JC, Alliot-Licht B, Baudouin C, Msika P, Bleicher F, Carrouel F: Odontoblast control of dental pulp inflammation triggered by cariogenic bacteria. Frontiers in Physiology 2013, 4:326.doi:10.3389/fphys.2013.00326.

17. Keller JF, Carrouel F, Colomb E, Durand SH, Baudouin C, Msika P, Bleicher F, Vincent C, Staquet MJ, Farges JC: Toll-like receptor 2 activation by lipoteichoic acid induces differential production of pro-inflammatory cytokines in human odontoblasts, dental pulp fibroblasts and immature dendritic cells. Immunobiology 2010, 215(1):53-59.doi:10.1016/j.imbio.2009.01.009.

18. Yumoto H, Hirao K, Hosokawa Y, Kuramoto H, Takegawa D, Nakanishi T, Matsuo T: The roles of odontoblasts in dental pulp innate immunity. The Japanese Dental Science Review 2018, 54(3):105-117.doi:10.1016/j.jdsr.2018.03.001.

19. Saklatvala J, Dean J, Finch A: Protein kinase cascades in intracellular signalling by interleukin-I and tumour necrosis factor. Biochemical Society symposium 1999, 64:63-77

20. Atta ur R, Harvey K, Siddiqui RA: Interleukin-8: An autocrine inflammatory mediator. Current pharmaceutical design 1999, 5(4):241-253

21. Tibbles LA, Woodgett JR: The stress-activated protein kinase pathways. Cellular and molecular life sciences : CMLS 1999, 55(10):1230-1254.doi:10.1007/s000180050369.

22. Christian F, Smith EL, Carmody RJ: The Regulation of NF-KB Subunits by Phosphorylation. Cells 2016, 5(1).doi:10.3390/cells5010012.

23. Chang J, Zhang C, Tani-Ishii N, Shi S, Wang CY: NF-kappaB activation in human dental pulp stem cells by TNF and LPS. Journal of Dental Research 2005, 84(11):994998.doi:10.1177/154405910508401105.

24. Huang $\mathrm{KH}$, Wang $\mathrm{CH}$, Lin $\mathrm{CH}$, Kuo HP: NF-kappaB repressing factor downregulates basal expression and mycobacterium tuberculosis induced IP-10 and IL-8 synthesis via interference with NF-kappaB in monocytes. Journal of biomedical science 2014, 21:71.doi:10.1186/s12929014-0071-5.

25. Dai H, Xu D, Su J, Jang J, Chen Y: Transmembrane protein 106a activates mouse peritoneal macrophages via the MAPK and NF-kappaB signaling pathways. Scientific Reports 2015, 5:12461.doi:10.1038/srep12461.

26. Pezelj-Ribaric S, Anic I, Brekalo I, Miletic I, Hasan M, Simunovic-Soskic M: Detection of tumor necrosis factor alpha in normal and inflamed human dental pulps. Archives of medical research 2002, 33(5):482-484

27. He W, Qu T, Yu Q, Wang Z, Wang H, Zhang J, Smith AJ: Lipopolysaccharide enhances decorin expression through the Toll-like receptor 4 , myeloid differentiating factor 88 , nuclear factorkappa $B$, and mitogen-activated protein kinase pathways in odontoblast cells. Journal of endodontics 2012, 38(4):464-469.doi:10.1016/j.joen.2011.12.021.

28. Ge XP, Gan YH, Zhang CG, Zhou CY, Ma KT, Meng JH, Ma XC: Requirement of the NF-kappaB pathway for induction of Wnt-5A by interleukin-1beta in condylar chondrocytes of the 
temporomandibular joint: functional crosstalk between the Wnt-5A and NF-kappaB signaling pathways. Osteoarthritis and cartilage 2011, 19(1):111-117.doi:10.1016/j.joca.2010.10.016.

29. Bonizzi G, Karin M: The two NF-kappaB activation pathways and their role in innate and adaptive immunity. Trends in immunology 2004, 25(6):280-288.doi:10.1016/j.it.2004.03.008.

30. Kim YS, Min KS, Lee SI, Shin SJ, Shin KS, Kim EC: Effect of proinflammatory cytokines on the expression and regulation of human beta-defensin 2 in human dental pulp cells. Journal of endodontics 2010, 36(1):64-69.doi:10.1016/j.joen.2009.09.022.

31. Xu F, Ren ZX, Zhong XM, Zhang Q, Zhang JY, Yang J: Intrauterine Inflammation Damages Placental Angiogenesis via Wnt5a-Flt1 Activation. Inflammation 2019, 42(3):818825.doi:10.1007/s10753-018-0936-y.

32. Zhang $\mathrm{Q}$, Liu J, Ma L, Bai N, Xu H: Wnt5a is involved in LOX-1 and TLR4 induced host inflammatory response in peri-implantitis. Journal of periodontal research 2019.doi:10.1111/jre.12702.

33. Sun M, Wang W, Min L, Chen C, Li Q, Weng W: Secreted frizzled-related protein 5 (SFRP5) protects ATDC5 cells against LPS-induced inflammation and apoptosis via inhibiting Wnt5a/JNK pathway. Journal of orthopaedic surgery and research 2021, 16(1):129.doi:10.1186/s13018021-02260-5.

34. Zou W, Wang X, Hong W, He F, Hu J, Sheng Q, Zhu T, Ran P: PM2.5 Induces the Expression of Inflammatory Cytokines via the Wnt5a/Ror2 Pathway in Human Bronchial Epithelial Cells. International journal of chronic obstructive pulmonary disease 2020, 15:26532662.doi:10.2147/copd.S270762.

35. Lin M, Li L, Liu C, Liu H, He F, Yan F, Zhang Y, Chen Y: Wnt5a regulates growth, patterning, and odontoblast differentiation of developing mouse tooth. Developmental dynamics : an official publication of the American Association of Anatomists 2011, 240(2):432440.doi:10.1002/dvdy.22550.

36. Peng L, Dong G, Xu P, Ren LB, Wang CL, Aragon M, Zhou XD, Ye L: Expression of Wnt5a in tooth germs and the related signal transduction analysis. Archives of oral biology 2010, 55(2):108114.doi:10.1016/j.archoralbio.2009.12.002.

37. Sugiuchi A, Sano Y, Furusawa M, Abe S, Muramatsu T: Human Dental Pulp Cells Express Cellular Markers for Inflammation and Hard Tissue Formation in Response to Bacterial Information. Journal of endodontics 2018, 44(6):992-996.doi:10.1016/j.joen.2018.02.022.

38. Yang G, Ju Y, Liu S, Zhao S: Lipopolysaccharide upregulates the proliferation, migration, and odontoblastic differentiation of NG2(+) cells from human dental pulp in vitro. Cell biology international 2019, 43(11):1276-1285.doi:10.1002/cbin.11127. 
Figure 1

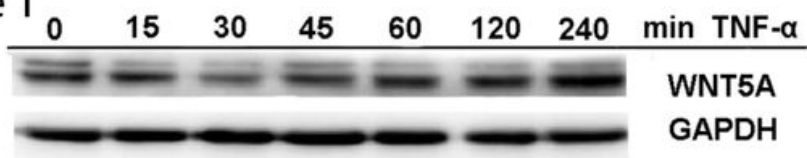

a

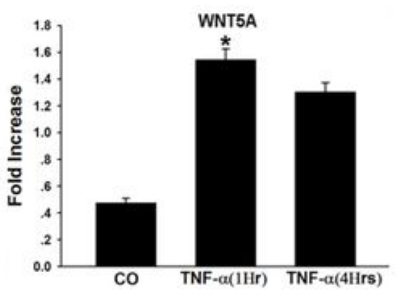

b

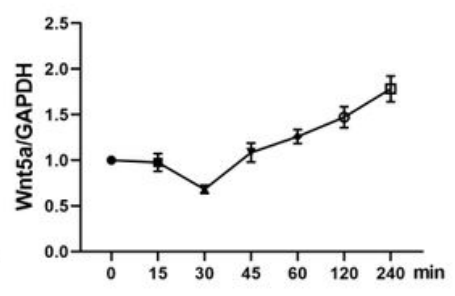

C
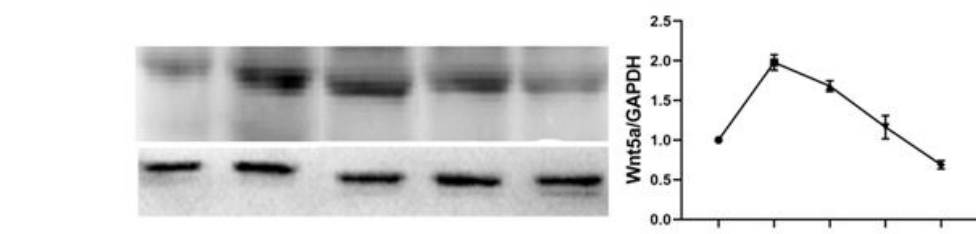

TNF- $a-++++$ TNF- $a_{-}++++$ $\mathrm{SB} 203580-+\quad+\quad+\quad+\mathrm{SB}_{2} 03580-{ }_{-}++$ SP600125 - $\quad-\quad-\quad+\quad+$ SP600125 - - - + $00126-\mathrm{f}^{-}+\mathrm{v} 0126-\mathrm{g}^{-}+$
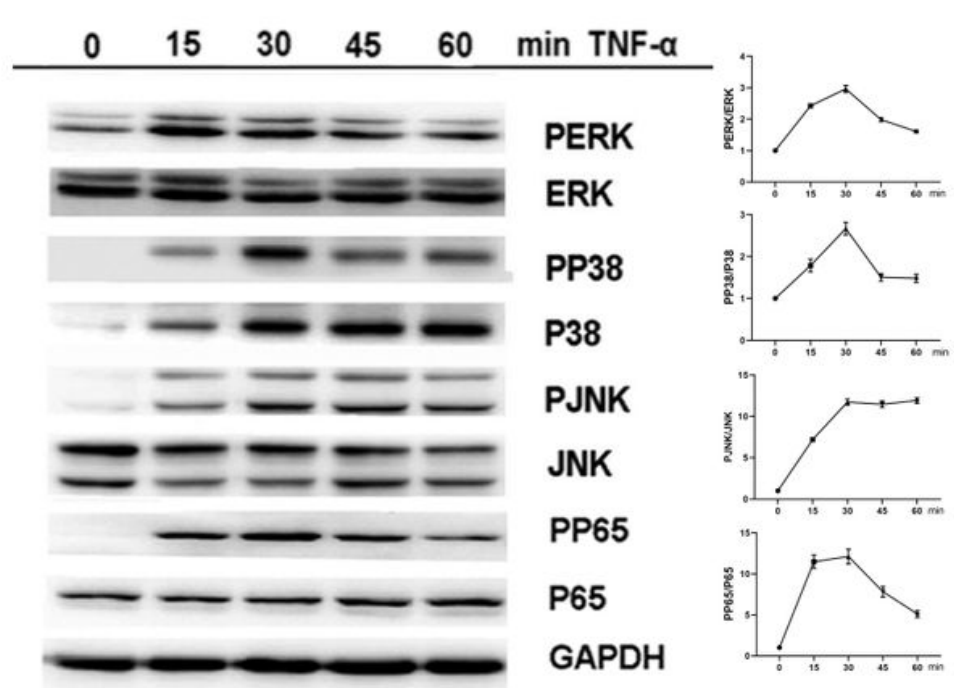

ERK

PP38

P38

PJNK

JNK

PP65

P65

GAPDH
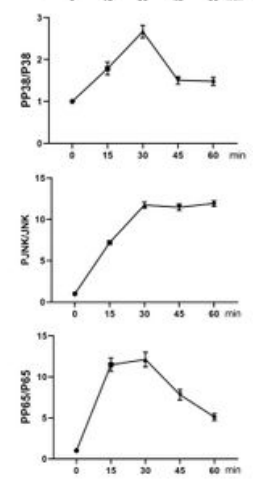

e

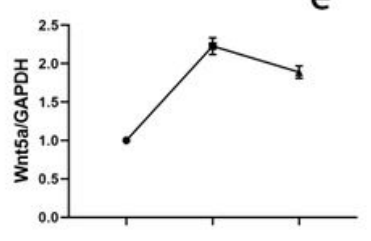

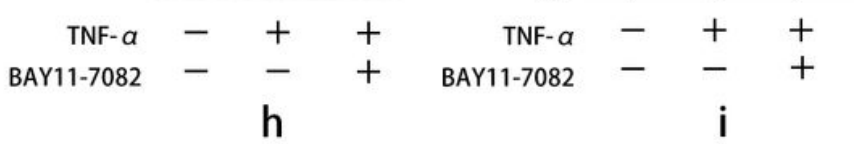

\section{Figure 1}

TNF-a induces the upregulation of Wnt5a through the MAPK and NF-KB pathways (these results are from different parts of the same gel). a, c: Western blot showing the protein expression of Wnt5a after odontoblasts were stimulated with TNF-a for the indicated time. b: Wnt5a mRNA expression in odontoblasts stimulated by TNF- $a$ for the indicated time. $d$ and e: Protein expression of total and phosphorylated ERK, P38, JNK, and P65after odontoblasts were stimulated with TNF-a for of the indicated time. $f$ and g: Effect of inhibiting the phosphorylation of ERK, P38, JNK, and P65 on Wnt5a expression. SP600125 (a JNK inhibitor), SB203580 (a p38 inhibitor), and U0126 (an ERK inhibitor). p-p38, phospho-p38; pJNK, phospho-JNK; pERK, phospho-ERK. GAPDH was used as a control. *, $p<0.05$ versus the control (CO). 
Figure 2

PP65

P65
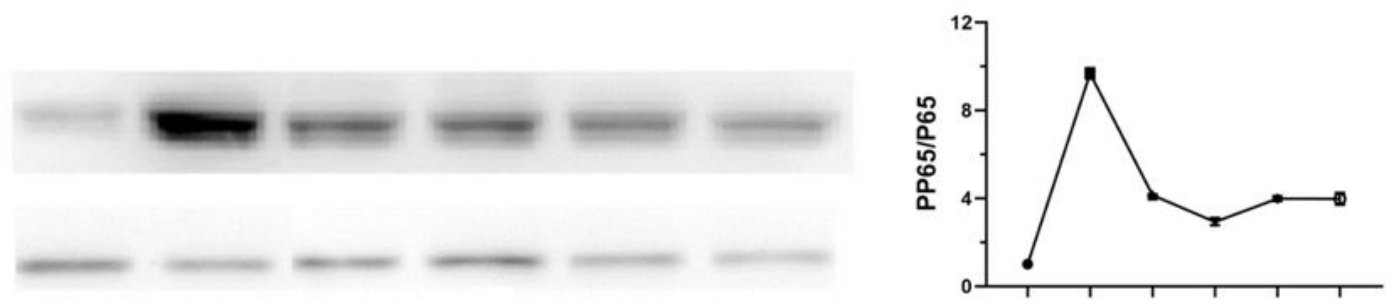

PP38

P38
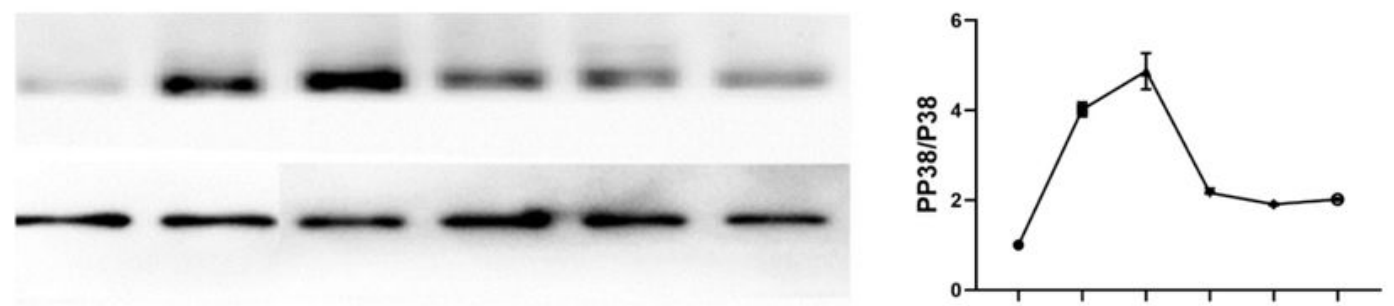

P-JNK

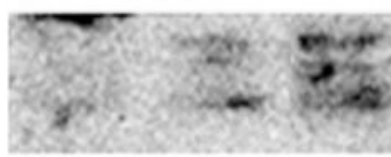

JNK
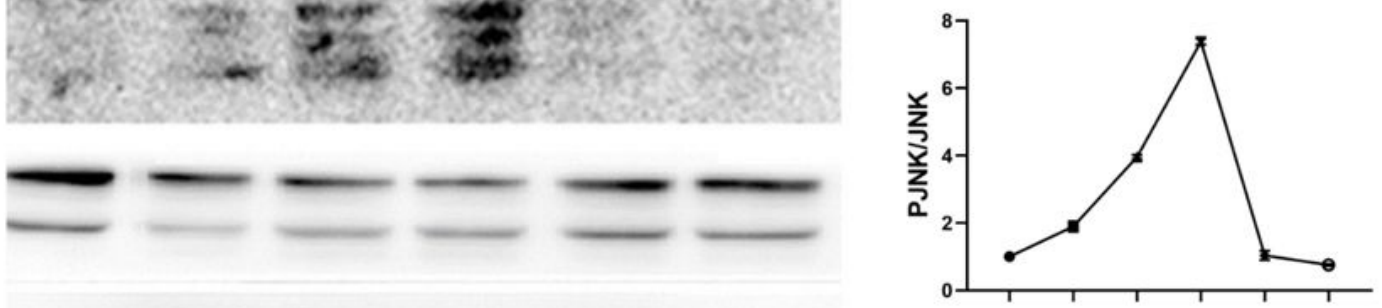

P-ERK

ERK

GAPDH
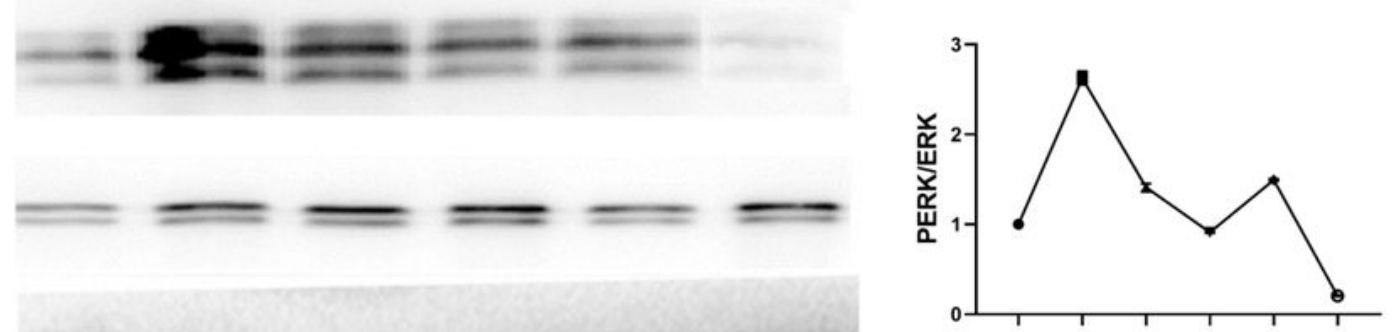

TNF- $\alpha$

$\begin{array}{llllllllllll}- & + & + & + & + & +\end{array}$

BAY11-7082 $-\quad-\quad+\quad+\quad-\quad-\quad-$

SB203580 -

SP600125 - $\quad-\quad-\quad-\quad-\quad+\quad+$

U0126

$\begin{array}{cccccc}- & - & - & - & - & +\end{array}$

Figure 2

Western blot detected the protein expression of NF-KB and MAPK pathways (these results are from different parts of the same gel). GAPDH was used as a control. PP65, phospho-65;PP38, phospho-P38; PJNK, phospho-JNK; PERK, phospho-ERK. BAY11-7082 (an NF-KB inhibitor); SP600125 (a JNK inhibitor), SB203580 (a p38 inhibitor), or U0126 (an ERK inhibitor). 
Figure 3
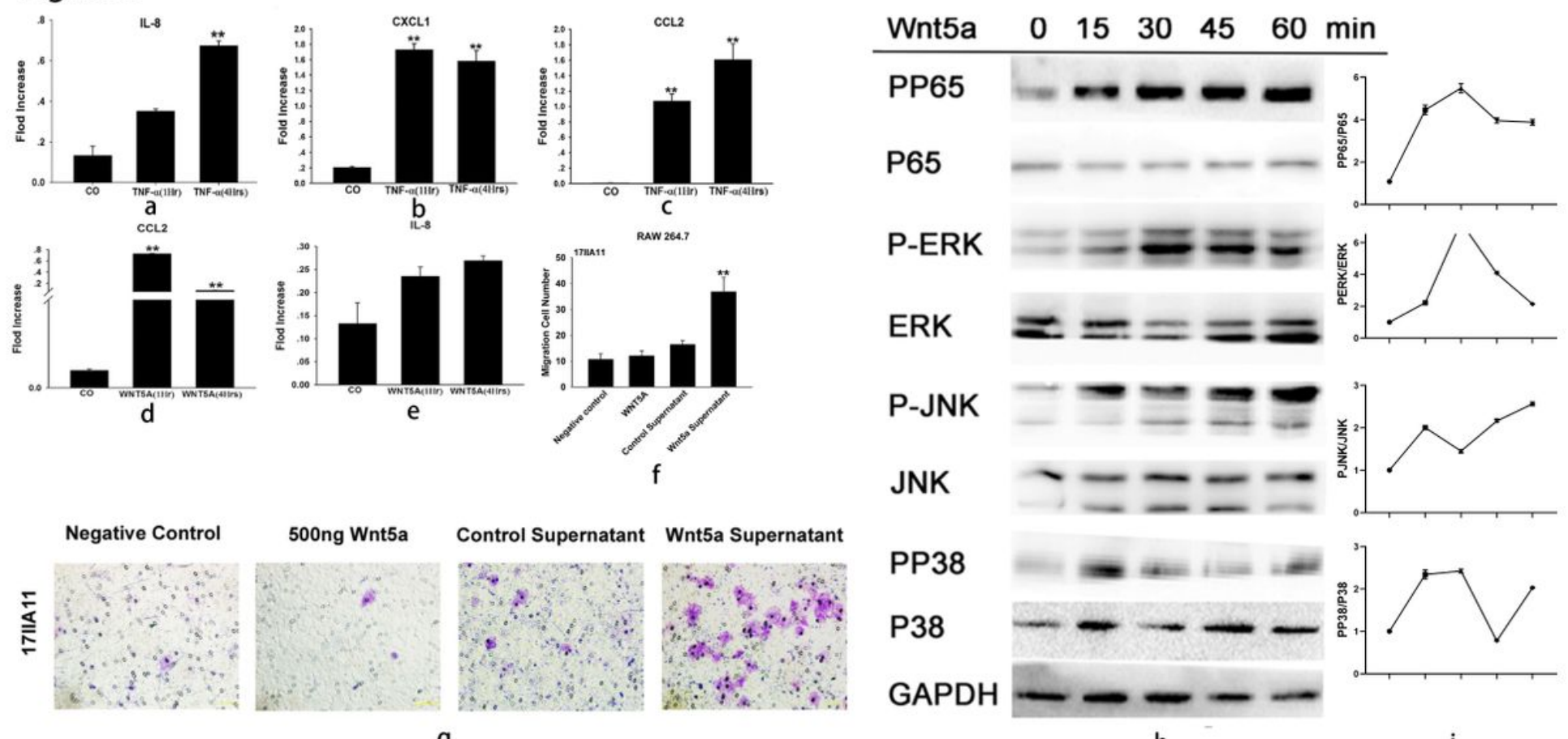

g
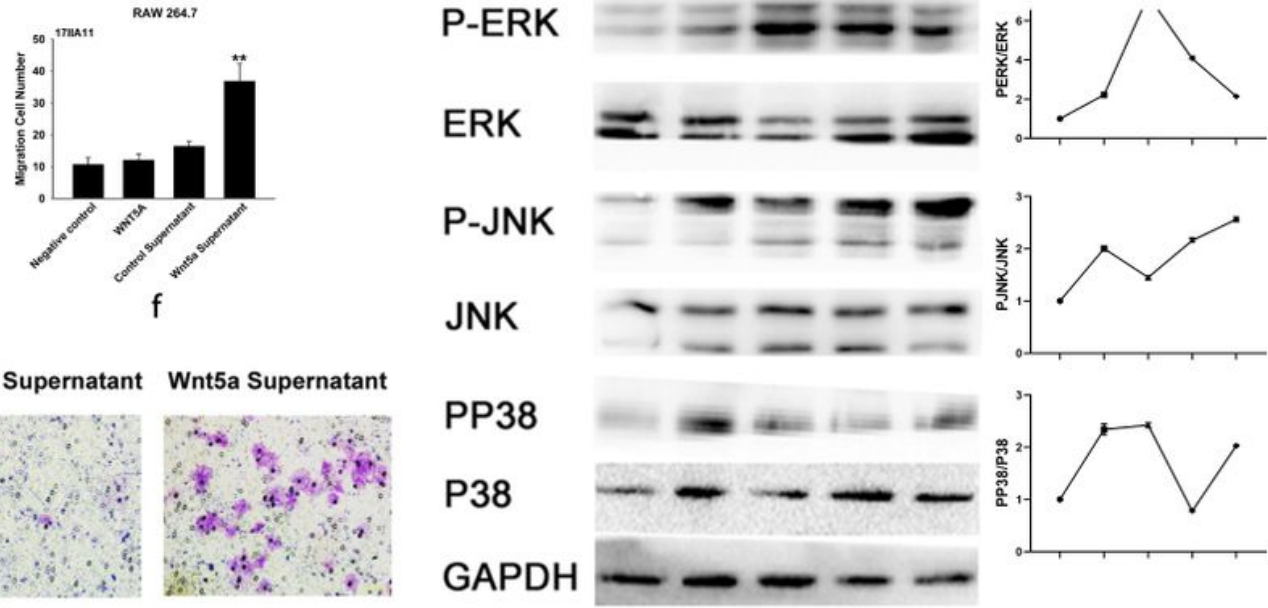

h

i

\section{Figure 3}

Wnt5a induces CCL2 expression and enhances macrophage migration. In addition, Wnt5a activates the MAPK and NF-KB signaling pathways. a-e: The mRNA expression of cytokines and chemokines. $\mathrm{f}, \mathrm{g}$ : Transwell detected the migration of RAW 264.7 cells. h: On the left side is the result that Western blot detected the protein expression of NF-KB and MAPK pathways (these results are from different parts of the same gel); on the right is the ratio of phosphorylated protein to non-phosphorylated protein of MAPK and NF-KB pathway related proteins. ${ }^{*}, \mathrm{p}<0.01$ versus the control. GAPDH was used as a control. 
Figure 4
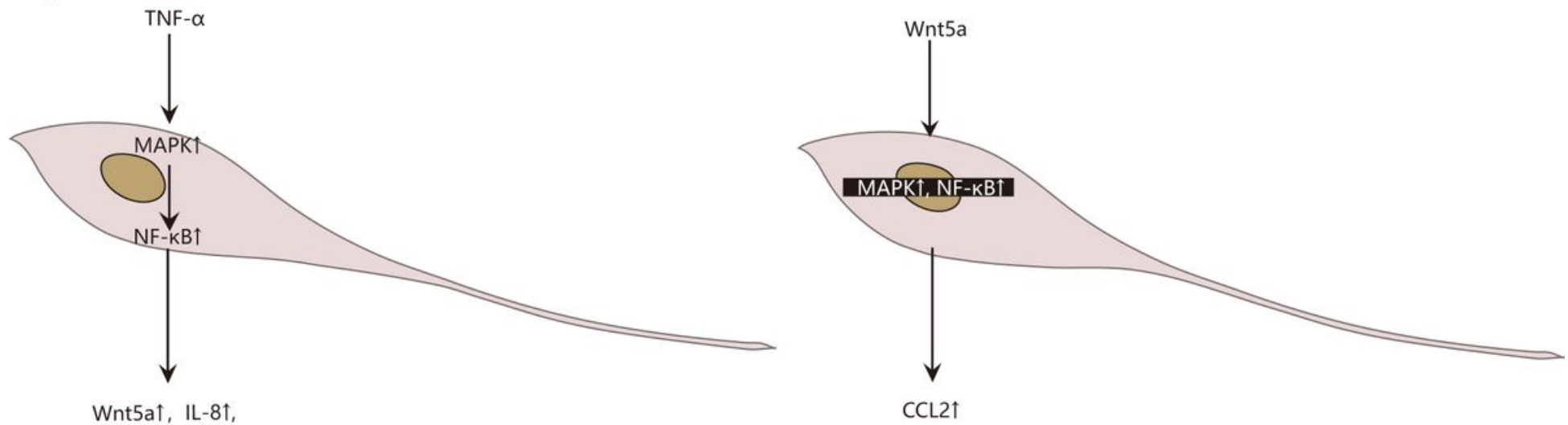

Wnt5a†, IL-81,

CXCL11, CCL2

a

b

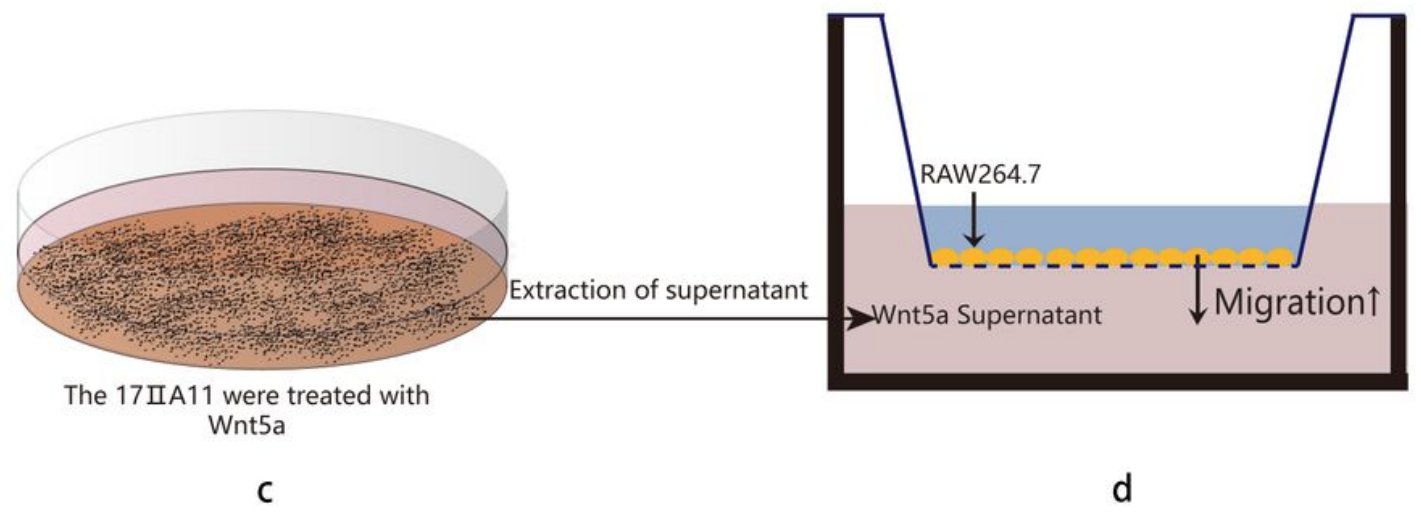

Figure 4

TNF-a promotes Wnt5a expression through MAPK and NF-KB activation in 17IIA11 cells and significantly upregulates IL-8, CXCL1, and CCL2 expression. b: Wnt5a activates the NF-KB and MAPK pathways and upregulates the expression of CCL2. c, d: The supernatant of 17IIA11 cells treated with Wnt5a promotes the migration of RAW264.7 cells. 